\title{
To evaluate the efficacy and safety of intravenous bolus versus intravenous infusion of iron sucrose in pregnant women with severe iron deficiency anemia
}

\author{
Urvashi Verma*, Saroj Singh, Shikha Singh, Anu Pathak, Poonam Yadav, Benazeer
}

Department of Obstetrics and Gynecology, S. N. Medical College, Agra, Uttar Pradesh, India

\author{
Received: 20 March 2017 \\ Accepted: 21 April 2017 \\ *Correspondence: \\ Dr. Urvashi Verma, \\ E-mail: drurvashiverma@ rediffmail.com
}

Copyright: () the author(s), publisher and licensee Medip Academy. This is an open-access article distributed under the terms of the Creative Commons Attribution Non-Commercial License, which permits unrestricted non-commercial use, distribution, and reproduction in any medium, provided the original work is properly cited.

\begin{abstract}
Background: Objective of present study was to evaluate the efficacy and safety of intravenous bolus iron sucrose for iron deficiency anemia during pregnancy during second and third trimester women presenting at S.N. medical college, Agra.

Methods: It was a prospective controlled trial and study was carried out in Department of Obstetrics and Gynecology, S.N. medical college, Agra in the year 2014-2016. 100Pregnant women with proved iron deficiency anemia having hemoglobin between $4-9 \mathrm{gm} / \mathrm{dl}$ was included in this study. Total Iron deficit was calculated by standard formula. Target haemoglobin was $11 \mathrm{gm} / \mathrm{dl}$. Iron sucrose was administered by intravenous bolus and intravenous infusion techniques. Hemoglobin was repeated at 2 weeks, 4 weeks and 8 weeks after the last dose of intravenous iron sucrose Results: In Group A (bolus group $n=50$ ) 22 women had gestational age $>24-28$ weeks and 20 women gestational age $>18-24$ weeks, with Mean gestational age of $24.36 \pm 3.78$ weeks. In Group B (infusion group $n=50$ ) most of the patients $24(48 \%)$ had gestational age >24-28 weeks, 18 (36\%) had gestational age >18-24 weeks, with Mean gestational age of $24.94 \pm 3.51$ weeks. Target hemoglobin was achieved in group A in all 50 (100\%) cases and in group $\mathrm{B}$ in $49(98 \%)$ cases. There were no allergic reactions.

Conclusions: This study showed a significant improvement in the hemoglobin of the patients after receiving intravenous bolus and intravenous infusion of iron sucrose. Patients achieved the target hemoglobin of $11 \mathrm{gm} / \mathrm{dl}$. Both therapies are safe, effective and faster acting for the treatment of iron deficiency anaemia during pregnancy. The bolus push technique is more convenient to women and care provider, less time consuming as well as cost effective.
\end{abstract}

Keywords: Hemoglobin, I/V Bolus, Iron deficiency anemia, Iron sucrose

\section{INTRODUCTION}

Anemia in pregnancy is an important public health problem worldwide. WHO estimates that more than half of the pregnant women in the world have a haemoglobin level indicative of anemia $(<11.0 \mathrm{gm} / \mathrm{dl})$, the prevalence may however be as high as 56 to $61 \%$ in developing countries. ${ }^{1}$ Women often become anemic during pregnancy because the demand for iron and other vitamins is increased due to physiological burden of pregnancy. The inability to meet the required level for these substances either as a result of dietary deficiencies or infection give rise to anemia. ${ }^{2}$

Anemia is estimated to affect nearly two thirds of the pregnant women in developing countries. Iron deficiency anemia is responsible for $95 \%$ of the anaemia during pregnancy. It is the commonest nutritional pathology in 
pregnant women. ${ }^{3}$ The incidence of anemia during pregnancy is estimated to be $40-80 \%$ in tropical countries. ${ }^{4}$ Anemia is responsible for $20 \%$ of maternal deaths in $3^{\text {rd }}$ world countries. About 500,000 maternal deaths per year and 20,000,000 maternal morbidity is due to anaemia during pregnancy globally. Among these patients about $47 \%$ of pregnant women suffer from moderate to severe anemia. ${ }^{5}$

Over the past years various routine methods like oral iron, intramuscular iron and blood transfusions were used to treat anemia during pregnancy, but these methods have some deficiencies. ${ }^{6-8}$

Intravenous iron sucrose therapy seems to be a safe, convenient and more effective method for treating anemia during pregnancy. ${ }^{9}$ The aim of this study was to evaluate the efficacy and safety of relatively new intravenous bolus and intravenous infusion of iron sucrose for iron deficiency anemia during pregnancy during second and third trimester.

\section{METHODS}

It was a prospective descriptive study, carried out at Obstetrics and Gynecology department of S.N. medical college Agra from 2014- 2016. 100 pregnant women between 14-32 weeks of gestation diagnosed as cases of iron deficiency anaemia with Haemoglobin level 4$9 \mathrm{gm} / \mathrm{dl}$ and serum ferritin level $<18 \mathrm{ng} / \mathrm{dl}$ attending the out patients department and wards were recruited in the study.

Written informed consent was obtained from all participants. After calculating the iron requirement, women were randomized to receive a multiple intravenous bolus iron sucrose (Group A, n=50) $200 \mathrm{mg}$ in $10 \mathrm{ml}$ of $0.9 \%$ normal saline as rapid bolus push over 5-10 minutes, administered through a venous butterfly cannula once the correct positioning in the vein had been tested with normal saline, and to receive a multiple intravenous infusion iron sucrose (Group B, n=50) $200 \mathrm{mg}$ in $100 \mathrm{ml}$ of $0.9 \%$ saline infusion over 30 minute, alternate days up to total calculated dose. All women were closely observed for up to 30 minutes for adverse reactions (after the first dose) such as nausea, burning sensation at infusion site, local pain, rashes and breathlessness during or immediately after the injection. During therapy vital signs like pulse rate, blood pressure, foetal heart rate and oxygen saturation were monitored during and 30 minute after iron therapy. All the patients were followed up on 2, 4 and 8 weeks after starting iron therapy. They were assessed for relief in symptoms, sign and laboratory parameters.

\section{RESULTS}

A total of 100 women consented to participate in the study, 50 women being randomized to Group A (24\% primigravidae and $76 \%$ multigravidae) and 50 to Group B
(20\% primigravidae and $80 \%$ multigravidae). The mean age, parity, period of gestation and socio-economic status were comparable in both groups. After the first dose, 7 of the 50 women in Group A $(14 \%)$ experienced minor adverse reactions while 6 of the 50 women in Group B $(12 \%)$.The nature of the adverse reactions were minor in both the groups. No women experienced any major side effects necessitating hospitalization.

Table 1: Distribution of cases according to parity.

\begin{tabular}{|lllll|}
\hline Parity & Group A & Group B \\
\hline 1 & No. & \% & No. & \% \\
\hline 2 & 12 & 24 & 10 & 20 \\
\hline 3 & 16 & 32 & 14 & 28 \\
\hline$>3$ & 12 & 24 & 14 & 28 \\
\hline Total & 10 & 20 & 12 & 24 \\
\hline p- & 50 & 100 & 50 & 100 \\
\hline
\end{tabular}

p-value $=0.8813$

Both groups had comparable pre-treatment $\mathrm{Hb}$ levels [Group A had mean $\mathrm{Hb}$ of $7.92 \mathrm{gm} / \mathrm{dl}( \pm \mathrm{SD} 0.89)$ and Group B had $\mathrm{Hb}$ of $8.18 \mathrm{gm} / \mathrm{dl}( \pm \mathrm{SD} 0.80)]$.

Table 2: Distribution of cases according to period of gestation.

\begin{tabular}{|lllll|}
\hline Period of & \multicolumn{2}{l}{ Group A } & \multicolumn{2}{l|}{ Group B } \\
\hline gestation (weeks) & No. & \% & No. & \% \\
\hline $14-18$ & 4 & 8 & 3 & 6 \\
\hline$>18-24$ & 20 & 40 & 18 & 36 \\
\hline$>24-28$ & 22 & 44 & 24 & 48 \\
\hline$>28-32$ & 4 & 8 & 5 & 10 \\
\hline Total & 50 & 100 & 50 & 100 \\
\hline Mean & $24.36 \pm 3.78$ & $24.94 \pm 3.51$ \\
\hline t-value & -0.7951 & & \\
\hline P value & 0.4285 & & \\
\hline
\end{tabular}

The mean haemoglobin level 2 weeks after starting therapy in group A was $8.96 \mathrm{gm} / \mathrm{dl}$ with an increase of $1.04 \mathrm{gm} / \mathrm{dl}$ from the pre-therapy haemoglobin level.

Table 3: Haemoglobin level before starting therapy.

\begin{tabular}{|lllll|}
\hline Hemoglobin & Group A & \multicolumn{3}{l|}{ Group B } \\
level $(\mathrm{gm} / \mathrm{dl})$ & No. & $\mathbf{\%}$ & No. & $\mathbf{\%}$ \\
\hline $4-6$ & 5 & 10 & 3 & 6 \\
\hline $6.1-8$ & 10 & 20 & 11 & 22 \\
\hline $8.1-9$ & 35 & 70 & 36 & 72 \\
\hline Total & 50 & 100 & 50 & 100 \\
\hline Mean & $7.92 \pm 0.89$ & & $8.18 \pm 0.80$ \\
\hline t-value & -1.5363 & & & \\
\hline P value & 0.1277 & & & \\
\hline
\end{tabular}

The groups are not significantly different

In group $\mathrm{B}$, the mean haemoglobin level 2 weeks of therapy was $9.19 \mathrm{gm} / \mathrm{dl}$ with an increase of $1.01 \mathrm{gm} / \mathrm{dl}$ in the haemoglobin level from the pre-therapy level. On 
statistically analysing the results, the difference was not significant $(\mathrm{P}=0.1087)$.

The mean haemoglobin level 4 weeks after starting therapy in group A was $10.15 \mathrm{gm} / \mathrm{dl}$ with an increase of $2.23 \mathrm{gm} / \mathrm{dl}$ from the pre-therapy haemoglobin level. In group B, the mean haemoglobin level 4 weeks of therapy was $10.26 \mathrm{gm} / \mathrm{dl}$ with an increase of $2.08 \mathrm{gm} / \mathrm{dl}$ in the haemoglobin level from the pre-therapy level. On statistically analysing the results, the difference was not significant $(\mathrm{P}=0.3584)$.
In group A, 4\% cases achieved target haemoglobin level 2 weeks after starting therapy, $60 \%$ cases achieved target haemoglobin level 4 weeks after starting therapy, $100 \%$ cases achieved target haemoglobin level 8 weeks after starting therapy. In group B, only $2 \%$ cases achieved target haemoglobin level 2 weeks after starting therapy, $64 \%$ cases achieved target haemoglobin level 4weeks after starting therapy, $98 \%$ cases achieved target haemoglobin level 8weeks after starting therapy on analysing the results, the difference was statistically not significant at 2 weeks, 4 weeks and 8 weeks after therapy $(\mathrm{P}>0.05)$.

Table 4: Achievement of target haemoglobin ( $\geq 11 \mathrm{gm} / \mathrm{dl}$ ) in both the groups at 2, 4 and 8 weeks after starting therapy.

\begin{tabular}{|c|c|c|c|c|c|c|c|c|c|c|c|c|}
\hline \multirow{3}{*}{$\begin{array}{l}\text { Hemoglobin } \\
\text { level (gm/dl) }\end{array}$} & \multicolumn{6}{|c|}{ Group A } & \multicolumn{6}{|c|}{ Group B } \\
\hline & \multicolumn{2}{|c|}{2 weeks } & \multicolumn{2}{|c|}{4 weeks } & \multicolumn{2}{|c|}{8 weeks } & \multicolumn{2}{|c|}{2 weeks } & \multicolumn{2}{|c|}{4 weeks } & \multicolumn{2}{|c|}{8 weeks } \\
\hline & No. & $\%$ & No. & $\%$ & No & $\%$ & No. & $\%$ & No. & $\%$ & No. & $\%$ \\
\hline$\geq 11$ & 2 & 4 & 30 & 60 & 50 & 100 & 1 & 2 & 32 & 64 & 49 & 98 \\
\hline$<11$ & 48 & 96 & 20 & 40 & - & - & 49 & 98 & 18 & 36 & 1 & 2 \\
\hline Total & 50 & 100 & 50 & 100 & 50 & 100 & 50 & 100 & 50 & 100 & 50 & 100 \\
\hline
\end{tabular}

Bolus push technique was found seven times cheaper than the slow infusion technique.

Table 5: Grade of adverse effects in both the groups.

\begin{tabular}{|lllll|}
\hline Grade of adverse & \multicolumn{2}{c|}{ Group A } & \multicolumn{2}{c|}{ Group B } \\
effect & No. & \% & No. & \% \\
\hline Grade I & 7 & 14 & 6 & 12 \\
\hline Grade II & - & - & - & - \\
\hline Total & 7 & 14 & 6 & 12 \\
\hline
\end{tabular}

\section{DISCUSSION}

In pregnancy, anaemia has a significant impact on the health of the foetus as well as mother. Foetuses are at risk of preterm deliveries, low birth weights, morbidity and perinatal mortality due to impairment of oxygen delivery to placenta and foetus. ${ }^{10}$

The responsible constellation of factors producing iron deficiency Anaemia generally precedes the pregnancy, including diet poor in iron content coupled with menstrual losses and a rapid succession of pregnancies in which supplemental iron was not provided. Most women begin their pregnancy with partially or completely depleted iron reserves. Thus, the severity of anaemia is inversely related to the amount of iron reserves. ${ }^{11}$ During pregnancy there is a great demand of iron to meet the requirement of red blood cell mass expansion in the mother, foetal and placental blood and blood loss at delivery. ${ }^{4,12}$ The use of bolus-push technique has potential for cost saving because of the avoidance of the need for a hospital bed and other paraphernalia associated with the conventional infusion technique currently used in the administration of iron. Present study shows that this is indeed a feasible approach, with similar efficacy to the conventional, and thereby corroborating the report by Macdougall et al who demonstrated the safety of $200 \mathrm{mg}$ iron sucrose administered as a 2-minute bolus-push in a total of 2297 injections. ${ }^{13}$

A study was conducted in India between November 2008 and February 2009 by Divakar $\mathrm{H}$ et al to compare the efficacy, safety and cost of two methods of administering intravenous iron sucrose, the conventional slow intravenous infusion versus the rapid bolus-push technique. ${ }^{14} 152$ pregnant women at 20-24 weeks gestation with iron deficiency anaemia ( $\mathrm{Hb}<11 \mathrm{~g} / \mathrm{dl}$ ) attending two rural antenatal clinics were randomized to receive $400 \mathrm{mg}$ intravenous iron sucrose either by the conventional slow infusion technique or by rapid bolus technique. There were no differences in mean rise of Haemoglobin between the two groups. No major adverse events necessitating hospitalization were reported in either group, same as in our study there were no difference in mean rise of $\mathrm{Hb}$ between the two groups.

So, in the present study we found that the mean haemoglobin level before starting therapy in group A was $7.92 \mathrm{gm} / \mathrm{dl}$ and in group B was $8.18 \mathrm{gm} / \mathrm{dl}$, there was an increase of $1.04 \mathrm{gm} / \mathrm{dl}$ in haemoglobin level after 2 weeks of therapy and mean haemoglobin level was $8.96 \mathrm{gm} / \mathrm{dl}$ in group A and in group B there was an increase of 1.01 $\mathrm{gm} / \mathrm{dl}$ in haemoglobin level and the haemoglobin level was $9.19 \mathrm{gm} / \mathrm{dl}$ at 2 weeks after therapy. This difference remain same at 4 weeks after therapy. The haemoglobin 
level was $10.15 \mathrm{gm} / \mathrm{dl}$ in group A (rise of $2.23 \mathrm{gm} / \mathrm{dl}$ ) at 4 weeks of therapy and in group B haemoglobin level was $10.26 \mathrm{gm} / \mathrm{dl}$ (rise of $2.08 \mathrm{gm} / \mathrm{dl}$ ). In group A $60 \%$ cases achieved the target haemoglobin at 4 weeks after therapy and $100 \%$ cases achieved target haemoglobin at 8 weeks after therapy. In group B, 64\% cases achieved the target haemoglobin at 4 weeks after therapy and $98 \%$ cases achieved target haemoglobin at 8 weeks after therapy.

In group A $88 \%$ cases were completely relieved of their symptoms at 4 weeks after therapy and in group B $90 \%$ cases were completely relieved of their symptoms. In group A $14 \%$ cases had grade I adverse effects and in group B $12 \%$ cases had grade I adverse effects. None of the case in both the groups had grade II adverse effects. The two groups were comparable with regards to patient demographics and pre-treatment haemoglobin. Following treatment both groups recorded a statistically significant increase in the mean haemoglobin level compared to baseline $(\mathrm{p}<0.05)$. However, there was no difference in two groups in rate/speed of mean rise of haemoglobin between the two groups.

\section{CONCLUSION}

In the present study, the cases selected in both the groups were comparable in terms of age, parity, period of gestation and socio-economic status. Following treatment both recorded a statistically significant increase in the mean haemoglobin level compared to baseline. Thus, we can conclude that both intravenous bolus and intravenous infusion of iron sucrose therapy are safe, convenient, effective and faster acting for the treatment of iron deficiency anaemia during pregnancy. Cost analysis revealed that the bolus push technique was seven times cheaper than the slow infusion technique.

But the bolus-push technique is a cost-effective approach to the treatment of iron deficiency anaemia during pregnancy than the slow infusion technique.

Funding: No funding sources

Conflict of interest: None declared

Ethical approval: The study was approved by the Institutional Ethics Committee

\section{REFERENCES}

1. World Health Organization, author. Prevention and Management of Severe Anaemia in Pregnancy: report of a technical working group. Geneva: 1994. WHL/FHE/MSM/93.3.
2. Idowu OA, Mafiena CF, Sotiloye D. Anemia in pregnancy: Asurvey of pregnant women in Abeukuta Niegeria. African Health Sience. 2005;5(4):295-9.

3. Allen LH. Pregnancy and iron deficiency: unresolved issues. Nut Rev. 1997;55:91-101.

4. Breymann C. Iron deficiency and anemia in pregnancy: modern aspects of diagnosis and treatment. Blood Cells Mol Dis. 2002;29:506-16.

5. WHO data presented at FIGO meeting in 2003 in Chile. Semin Hematol. 2006;43(Supple 6):528-31.

6. Perewusny KG, Huck R, Huck A, Breymann C. Parenteral iron sucrose complex. $\mathrm{Br} \mathrm{J}$ Nutr. 2002;88:3-10.

7. Al- Momen A K, Al- Meshari A, Al-Nuaim L, Saddique A, Abutalin Z, Khashogi $\mathrm{T}$, et al. Intravenous iron sucrose complex in the treatment of iron deficiency anemia during pregnancy. Eur $\mathbf{J}$ Obstet Gynecol Reprod Biol. 1996;69:121-4.

8. Bayoumeu F, Subiran-Busset C, Baka NE, Legagneur H, Monnier-Barbarino P, Laxenaire M C. Iron therapy in iron deficiency anemia in pregnancy: Intravenous route versus oral route. Am J Obstet Gynecol. 2002;186:518-22.

9. Wali A, Mushtaq A, Nilofer. Comparative studyefficacy, Safety and compliance of intravenous iron sucrose and intramuscular iron sorbitol in iron deficiency anemia of pregnany. J Pak Med Assoc. 2002;52(9):392-5.

10. Harrison KA. Maternal mortality and anaemia in pregnancy. W Afr Med J. 1975;23:27-31.

11. Yaqoob N, Abbasi SM. Nutritional iron deficiency in our population. J Coll Physicians Surg Pak. 2002;12:395-7.

12. Breymann C. Anemia working group. Current aspects of diagnosis and therapy of iron deficiency anemia in pregnancy. Schweiz Rundsch Med Prax. 2001;90:1283-91.

13. Macdougall IC, Roche A. Administration of intravenous iron sucrose as a 2-minute push to CKD women: a prospective evaluation of 2,297 injections. Am kidney Dis. 2005;46(2):283-9.

14. Diwaker H, Gautham MS, Maryonda IT, Rapid verses slow $\mathrm{i} / \mathrm{v}$ iron sucrose administration in an Indian rural pregnant population with iron deficiency anemia. J Perinatal Neonatal Care. 2011;12(2):45- 7.

Cite this article as: Verma $U$, Singh $S$, Singh $S$, Pathak A, Yadav P, Benazeer. To evaluate the efficacy and safety of intravenous bolus versus intravenous infusion of iron sucrose in pregnant women with severe iron deficiency anemia. Int J Reprod Contracept Obstet Gynecol 2017;6: 2417-20. 